\title{
CISTO DE DUPLICAÇÃO GÁSTRICA COM PARÊNQUIMA PANCREÁTICO ECTÓPICO EM ADULTO ASSINTOMÁTICO
}

\author{
DUPLICATION CYST OF THE STOMACH WITH ECTOPIC PANCREATIC TISSUE \\ IN AN ASYMPTOMATIC ADULT
}

\author{
Kanthya Arreguy de Sena ${ }^{1}$ \\ Guilherme Durães Rabelo, TCBC-MG² \\ Walton Albuquerque, TCBC-MG
}

\section{INTRODUÇÃO}

A duplicação gastro-intestinal é uma afecção congênita pouco freqüente, rara na topografia do estômago (4\% das duplicações de vísceras ocas), com menos de 100 casos descritos na literatura internacional. Como os cistos de duplicação gástrica (CDG) são congênitos e a maioria sintomáticos, são geralmente diagnosticados e tratados na infância.

Relatamos o caso de um CDG contendo mucosa pancreática ectópica em paciente adulto assintomático.

\section{RELATO DO CASO}

Paciente 55 anos, masculino, em outubro de 1999, manifestou epigastralgia devido a úlcera duodenal diagnosticada por endoscopia digestiva alta (EDA). Após tratamento clínico, tornou-se assintomático. Em agosto de 2001, EDA de controle identificou abaulamento na cárdia, com saída de secreção brancacenta (Figura 1). As biópsias da região foram negativas para malignidade. Ultrassonografia (US) de abdome detectou imagem nodular, caudal à junção esofago-gástrica, com aproximadamente $29,9 \mathrm{~cm}^{3}$, de conteúdo líquido. A eco-endoscopia com probe de 7,5 e $15 \mathrm{mHz}$ constatou cisto perigástrico, sem alterações na integridade da parede do estômago. A colangiopancreatografia endoscópica retrógrada mostrou vias biliares e ducto pancreático com aspectos anatômicos usuais. A tomografia computadorizada (TC) de abdome identificou formação ovalada de contornos regulares, adjacente à pequena curvatura gástrica, sugestiva de CDG (Figura 2). A impossibilidade de excluir lesão neoplásica motivou a indicação cirúrgica. Durante o ato cirúrgico, foi constatado cisto de aproximadamente

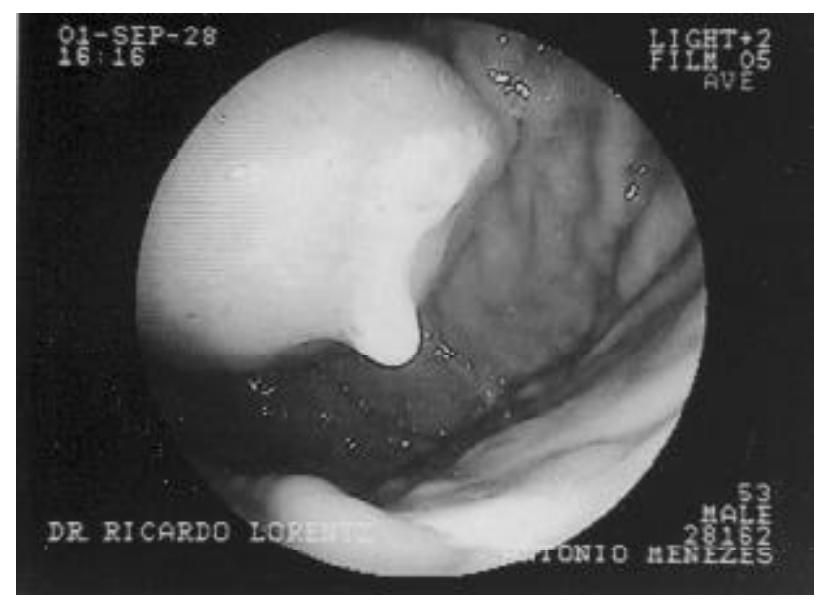

Figura 1- Abaulamento na cárdia gástrica com saída de secreção brancacenta à EDA.

1. Residente de Cirurgia Geral do Hospital Felício Rocho e Hospital Pronto Socorro João XXIII- FHEMIG - Belo Horizonte- Minas Gerais - Brasil.

2. Médico Cirurgião dos Hospitais Felício Rocho e Hospital Pronto Socorro João XXIII; Professor Assistente da Faculdade Ciências Médicas; Instrutor do Curso PHTLS e Preceptor da Residência Médica de Cirurgia do Hospital Felício Rocho- Belo HorizonteMinas Gerais- Brasil.

3. Coordenador do Serviço de Endoscopia Digestiva do Instituto Alfa de Gastroenterologia do Hospital das Clínicas da UFMG e do Hospital Militar de Minas Gerais e Endoscopista do Hospital Felício Rocho- Belo Horizonte - Minas Gerais - Brasil. 


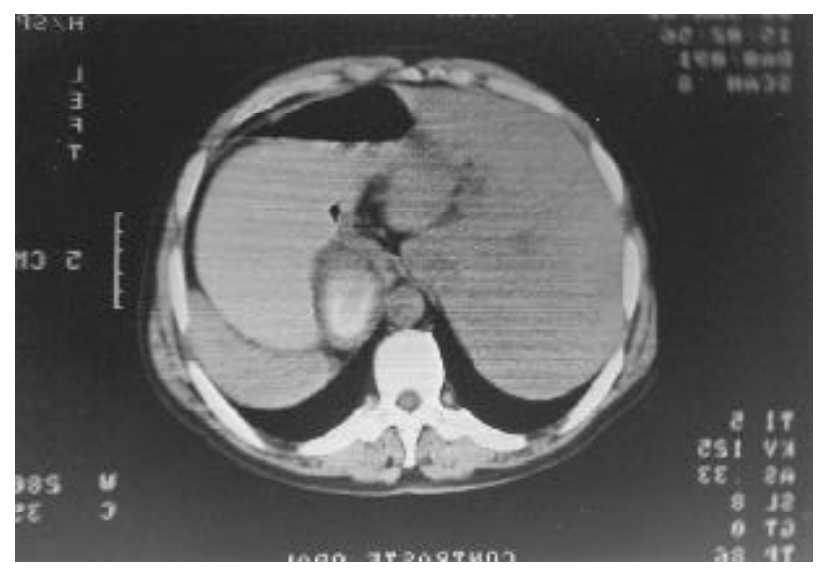

Figura 2 - TC do abdome mostrando formação ovalada de limites precisos, contornos regulares, medindo 7,0 $\times 4,2 \times 4,0$ cm iniciando-se ao nível da junção esôfago-gástrica, sugestiva de CDG.

$6 \mathrm{~cm}$ de diâmetro junto ao fundo gástrico com pequeno óstio de comunicação com a luz deste órgão, sem evidências macroscópicas de malignidade (Figura 3). Realizada ressecção da massa. O estudo anatomopatológico revelou camadas serosa, muscular e mucosa de padrão histológico gástrico com sinais de inflamação aguda e pequena área de tecido pancreático ectópico exócrino e endócrino. A dosagem da amilase do conteúdo do cisto foi superior a $4000 \mathrm{u} / \mathrm{ml}$.

\section{DISCUSSÃO}

A definição anatômica dos CDG requer a presença de estrutura tubular em íntimo contato com o estômago, contendo camada muscular e nutrição sangüínea própria ${ }^{2}$. Podem ou não comunicar com a luz gástrica ${ }^{3}$. Em muitos casos, são encontrados no interior dessas estruturas tecidos pancreático, colônico, ileal ou jejunal ${ }^{2}$. A etiologia ainda não se encontra bem estabelecida, mas acredita-se que se formam pela invaginação e fusão do epitélio longitudinal encontrado no período fetal da organogênese ${ }^{4}$.

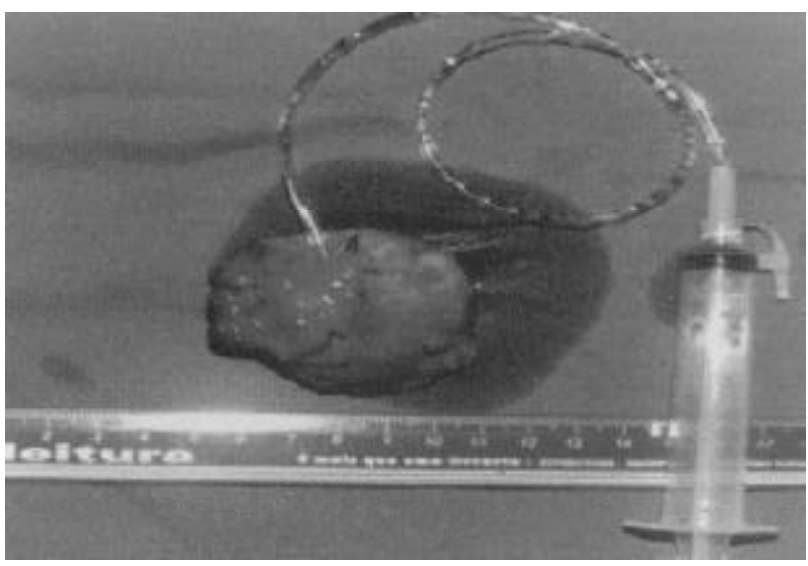

Figura 3 - Peça cirúrgica: em detalhe, pequeno óstio de comunicação com a luz gástrica.

A identificação dos cistos gástricos, usualmente, se faz através da EDA ${ }^{2}$. Eles são mais comuns na grande curvatura, mas podem ser encontrados em íntimo contado com qualquer parte da parede gástrica ${ }^{5}$. As manifestações clínicas dos CDG decorrem de suas complicações e topografia, a saber: obstrução pilórica por compressão quando junto ao antro, pancreatite aguda decorrente da obstrução do ducto pancreático por secreções viscosas provenientes do cisto, se há comunicação entre eles, e hemorragia e perfuração devido a formação de úlceras pépticas no epitélio do mesmo ${ }^{1}$. A US e TC auxiliam na localização da lesão. Quando os cistos são pequenos, podem ser confundidos com massas submucosas como leiomioma ou lipoma. Ao adquirirem proporções maiores, sugerem doenças de órgãos adjacentes como pseudocisto de pâncreas, massa renal, esplenomegalia ou sarcoma retroperitoneal. $\mathrm{O}$ tratamento preconizado é a ressecção do cisto.

O CDG, apesar de raro, deve ser considerado no diagnóstico diferencial das massas no abdome superior. A EDA, US e TC ajudam no diagnóstico, porém a confirmação só se faz através da laparotomia e estudo anatomopatológico da peça.

\begin{abstract}
The authors describe a rare case of a gastric duplication cyst in a 55-year-old man. The past history revealed that the patient was treated one year before for gastroduodenal ulcer. The cyst was discovered incidentally at upper gastrointestinal endoscopy. Biopsies showed inflammation without evidence of tumor. On abdominal ultrasonography and CT scan, a left upper quadrant mass was noted. At laparotomy, a mass measuring 6,0 cm in contact with the stomach was excised. Histopathology showed a gastric duplication cyst containing pancreatic mucosa.
\end{abstract}

Key Words: Choristoma; Stomach; Pancreas; Adult. 


\section{REFERÊNCIAS}

1. Engler-Pinto P, Arab-Fadul R, Waitzberg DL, et al. Duplicação gástrica com ectopia pancreática. An Paul Med Cir , 1993, 120(2): 33-37.

2. Koltun WA - Gastric duplication cyst. Endoscopic presentation as an ulcerated antral mass. Am Surg, 1991, 57(7): 468-473.

3. Johnstone DW, Forde KA, Markowitz D et al. - Gastric duplication cyst communicating with the pancreatic duct: a rare cause of recurrent abdominal pain. Surgery, 1991, 109(1): 97-100.
4. Glaser C, Kuzinkovas V, Maurer C et al. - A large duplication cyst of the stomach in an adult presenting as pancreatic pseudocyst. Dig Surg, 1998, 15(6): 703706.

5. Kim DH, Kim JS, Nam ES et al. - Foregut duplication cyst of the stomach. Pathol Int, 2000, 50(2): 142-145.

Endereço para correspondência:

Kanthya Arreguy de Sena

Endereço: Rua Itambé, 35 - apto. 401 - Bairro Floresta

CEP: 30150-150- Belo Horizonte - Minas Gerais - Brasil

E-mail: Karreguy@uol.com.br

Tel/fax consultório: (31) 32951832

Celular: (31) 96138512 